\title{
Effects of deviations from thermo-rheologically simple behavior of asphalt mixes in creep on developing of master curves of their stiffness modulus
}

\author{
Mariusz Jaczewski, Józef Judycki \\ Department of Civil and Environmental Engineering, Gdansk University of Technology, Narutowicza Street 11/12, 80-952 Gdansk, Poland
}

\begin{abstract}
The paper presents the deviations from the thermo-rheologically simple behavior of asphalt mixes and their effects on the developing of master curves of stiffness modulus. Eleven different mixes were tested in three point bending test under constant load at temperatures $-20^{\circ} \mathrm{C},-10^{\circ} \mathrm{C}$ and $0{ }^{\circ} \mathrm{C}$, and in some cases at $+10^{\circ} \mathrm{C}$. The test method was developed at the Gdansk University of Technology, Poland. The applied stress level was approximately equal to $30 \%$ of the flexural strength. It was found that the stiffness moduli of tested asphalt mixes at a certain low temperature and at a long time of loading greater than $600 \mathrm{~s}$ or $1200 \mathrm{~s}$ tended to the constant values unrelated to the time of loading. It resulted from the diminishing of viscoelastic flow of the material at long loading time at low temperature. Therefore, the stiffness modulus at long loading time was dependent upon temperature but was almost not related to the loading time. In most cases at temperatures $-20{ }^{\circ} \mathrm{C}$ and at $-10^{\circ} \mathrm{C}$ a clear deviation from the time-temperature superposition principle was observed. These deviations were dependent on the type of bitumen used, type of asphalt mixture and the value of applied stresses. The deviations from thermoreologically simple behavior affected the formation of the master curve of stiffness modulus and might cause increase of thermal stresses in asphalt layers of pavements and disappearance of stress relaxation.
\end{abstract}

Keywords: asphalt mix; creep; rheological properties; low-temperature properties; thermo-reological simplicity, time-temperature superposition.

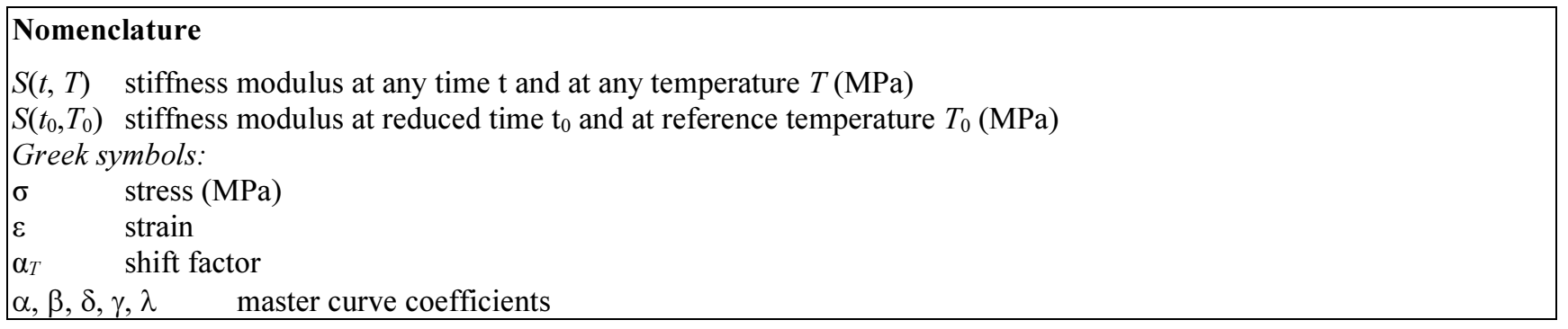

\section{Introduction}

Analysis of viscoelastic properties of bitumens and asphalt mixes is generally based on the assumption that they are thermorheologically simple materials and subject to the time-temperature superposition principle. The time-temperature superposition principle first was used for polymers by Ferry [1] and afterwards from 1960s was applied for asphalt mixes by Monismith et al. [2]. The concept is very useful and has been widely applied in research on bitumens and asphalt mixes till present time. In most cases the behavior of asphalt mixes is consistent with this principle. In the paper by Schwartz, Gibson and Schapery [3] it was found that in unconfined uniaxial compression the time-temperature superposition was valid not only for small strains $(<100 \mu \mathrm{s})$ but also for large induced strains. It was later confirmed by Schwartz et al. [4] for large strain viscoplastic regime at elevated temperatures. Zhao and Kim [5] used repeated creep and recovery tests and the cyclic

Corresponding author: Józef Judycki. E-mail address: jozef.judycki@wilis.pg.gda.pl

http://dx.doi.org/10.3846/enviro.2014.157

(C) 2014 The Authors. Published by VGTU Press. This is an open-access article distributed under the terms of the Creative Commons Attribution License, which permits unrestricted use, distribution, and reproduction in any medium, provided the original author and source are credited. 
sinusoidal loading test and found that the time-temperature superposition principle was valid for tested asphalt mixes from +5 to $+55^{\circ} \mathrm{C}$.

The validity of thermo-rheological simplicity of bitumens and asphalt mixes was accepted by and applied in current standards. The standard AASHTO T 342-11 utilizes the time-temperature superposition principle for determining the dynamic modulus of hot-mix asphalt concrete mixes. The time-temperature superposition principle is also used by the standard AASHTO MP1a for determining the critical temperature for low-temperature cracking.

Despite the fact that the thermo-rheological simplicity of asphalt mixes is widely accepted, some deviations of bitumens and asphalt mixes from the time-temperature superposition principle was also noted. Yusoff, Chailleux and Airey [6] found that some bitumens and bitumen-filler mastics demonstrated a deviation from the thermorheological simplicity of the rheological behavior, especially for highly structured bitumens, for polymer modified bitumens with high degree of polymer modification and for bitumens after oxidative ageing. Palade, Attane and Camaro [7] found pronounced deviations from thermorheological simplicity for some tested bitumens and mastics. Marasteneanu, Basu, Hesp and Voller [8] tested asphalt binders and found that the stiffnesses of bitumens at low temperature predicted from the time-temperature superposition principle were slightly higher than tested values. They concluded that one of possible reasons could be a deviation of bitumens from the thermo-rheological simplicity.

The authors of this paper found that at low temperature some tested asphalt concretes exhibited evident deviations from thermo-rheological simplicity. At very low temperatures some asphalt concretes behaved like a solid materials and their creep under constant load in bending, after long time of loading, completely stopped or strongly decreased what resulted in almost the same value of stiffness which was independent of the time of loading. Such behavior at low temperature would cause increase of thermal stresses in asphalt layers of pavements and disappearance of stress relaxation. The paper presents the concept of thermo-rheological simplicity of asphalt mixes, tested materials, testing methods and the effect of deviation from thermo-rheological simplicity on formation of master curves of stiffness of asphalt concrete.

\section{Essence of the deviations from the thermo-rheological simplicity}

The materials which deviate from the thermo-rheological simplicity do not comply with the time-temperature superposition principle. The principle of the time-temperature superposition is the following. Assume that the creep test was performed at two temperatures $T_{1}$ and $T_{2}$ under stresses $\sigma_{1}$ and $\sigma_{2}$. The induced strains $\varepsilon_{1}$ and $\varepsilon_{2}$ were recorded and mix stiffness $S$ was calculated from Eqn. (1), as a function of time $t$ and temperature $\mathrm{T}$ :

$$
S(t, T)=\sigma / \varepsilon(t, T)
$$

Figures 1a, 1b and 1c present results typical for an asphalt mix which behaves in accordance with the principle of timetemperature superposition principle. Fig. la shows the creep curve of the mix which after a long time of constant loading reaches a constant rate of viscous flow. Such behavior is typical for "liquid class of materials" and can be described with the Burgers model. The stiffness curves are presented in Fig. 1b in logarithmic scale. Isothermal curves of stiffness "log S-log t" in Fig. 1b can be shifted along the time axis in such a way that they completely coincide. The shift is equal to log $\alpha_{\mathrm{T}}$, where $\alpha_{\mathrm{T}}$ is the shift factor. The stiffness of the mix at any time and temperature $S(t, T)$ can be calculated from the Eqns (2) and (3):

$$
\begin{array}{r}
S(t, T)=S\left(t_{0}, T_{0}\right) \\
t_{0}=t / \alpha_{T}
\end{array}
$$

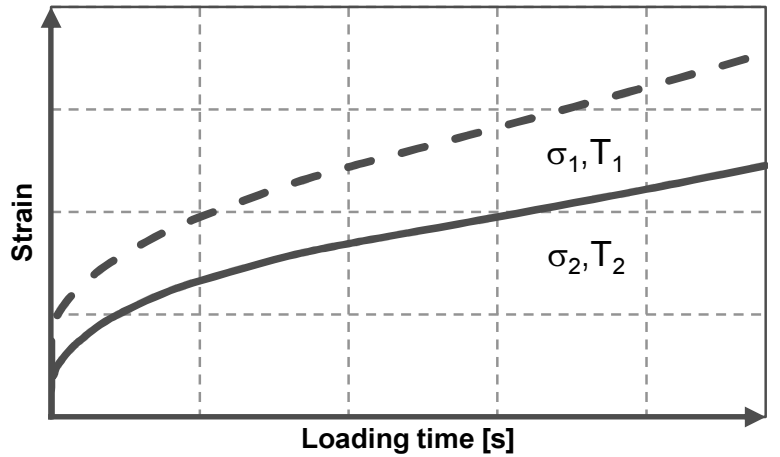

(a)

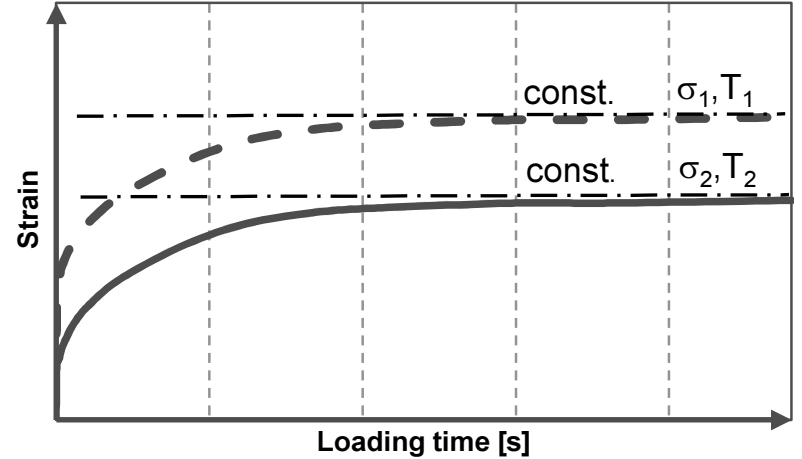

(d) 


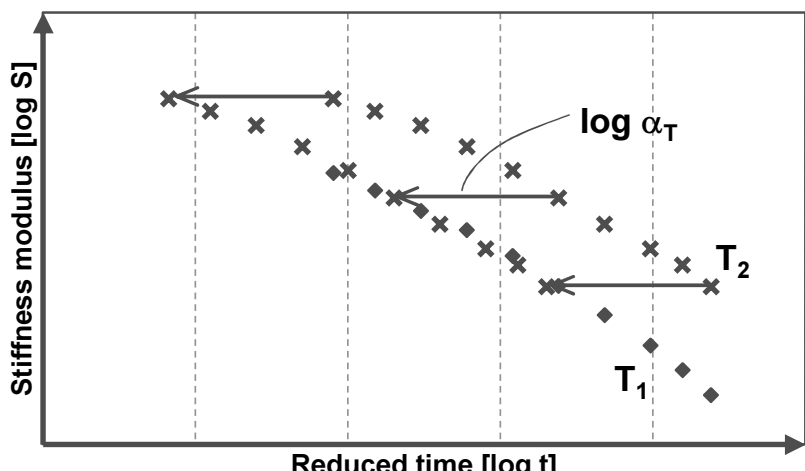

(b)

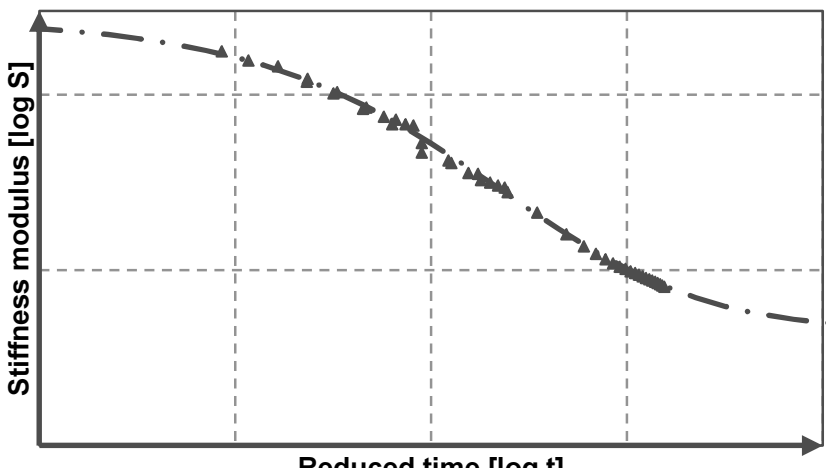

Reduced time [log $\mathbf{t}]$

(c)

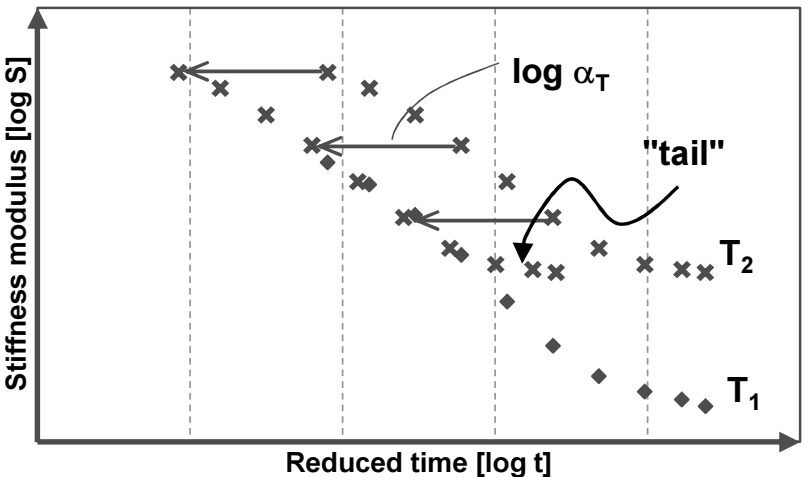

(e)

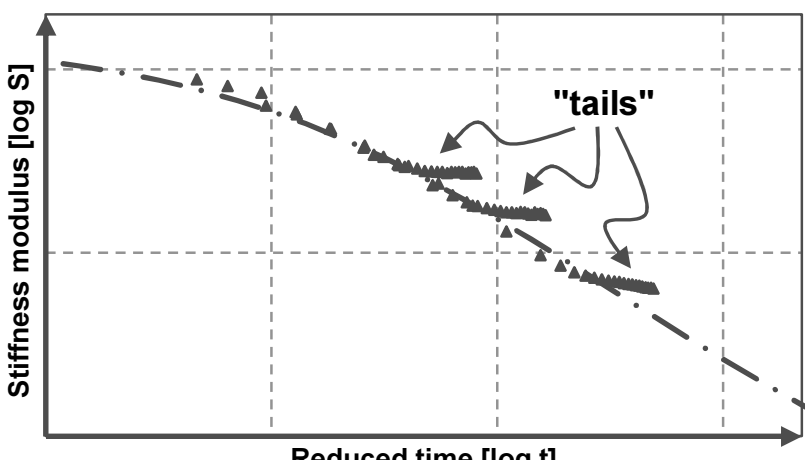

(f)

Fig. 1. Different behavior of asphalt mixes; (a), (b), (c) - materials which comply with time-temperature superposition principle; (d), (e), (f) - materials which do not comply with time-temperature superposition principle; (a) and (d) - creep curves; (b) and (e) stiffness moduli;

(c) and (f) - master curves of stiffness moduli

The shift factor $\alpha_{T}$ can be determined in various ways, using one from the following equations: empirical log-linear equation, Wiliam-Landel-Ferry (WLF) equation, Arrhenius equation, and/or modified Kaeble equation. For thermorheologically simple asphalt mixes, if creep tests are performed at several (at least 3 or better 5) temperatures a smooth master curve $\mathrm{S}\left(t_{0}, T_{0}\right)$ can be obtained, as shown in Fig. 1c.

Figures 1d, 1e and 1f present results typical for an asphalt mix which does not comply with the principle of timetemperature superposition principle. The typical creep curve for an asphalt mix which deviates from the time-temperature superposition principle is shown in Fig. 1d. Fig. 1d shows the creep curve of the mix which after a long time of constant loading reaches a constant (or nearly constant) value of strain and does not exhibit any further viscous flow. Such behavior is typical for "solid type of materials" and can be described with the Zener model. Some tested asphalt concretes showed such behavior at low temperatures equal to or less than $-10{ }^{\circ} \mathrm{C}$. Fig. 1e shows stiffness curves for such materials in logarithmic scale. It can be seen that after long loading time the stiffness of the mix reaches a constant value for a given temperature $T_{1}$ and $T_{2}$. After shifting along the time axis the stiffness curves at $T_{1}$ and $T_{2}$ only partly coincide at short time of loading and do not coincide for long time of loading. For mixes which deviate from the thermo-rheological simplicity, if creep tests are performed at several (at least 3 or better 5 ) temperatures a master curve $\mathrm{S}\left(t_{0}, T_{0}\right)$ can be obtained, as shown in Fig. 1f, but the master curve is not smooth but with characteristic "tails" for each testing low temperature below $-10{ }^{\circ} \mathrm{C}$.

The described deviations from the thermo-rheologically simple behavior were observed by the authors in two cases, firstly, for asphalt concretes containing rather hard bitumens at low temperatures equal to or less than $-10^{\circ} \mathrm{C}$ and secondly, for low temperatures equal to or less than $-10^{\circ} \mathrm{C}$ and for very low bending stresses during laboratory testing. In the second case, under very low stresses, such behavior was possible not only for asphalt mixes containing hard bitumens but also if softer bitumens were used.

\section{Materials}

For the purpose of this study eleven different asphalt mixtures were tested:

- AC $16 \mathrm{~W}$ asphalt concrete for binder course with 35/50 and 50/70 neat bitumens,

- AC WMS 16 high modulus asphalt concrete for binder and base courses with 20/30 neat bitumen, 25/55-60 SBS modified bitumen and 20/30 multigrade bitumen,

- SMA 8 stone mastic asphalt with 45/80-55 SBS modified bitumen,

- PA 8 porous asphalt with $45 / 80-55$ SBS modified bitumen. 
The composition of mixes, their grading curves and optimum bitumen content, were designed according to the WT-2 (2010) Polish technical guidelines. Granite aggregate and limestone filler were used in all mixtures. All tested asphalt mixtures were compacted in $300 \times 300 \times 50 \mathrm{~mm}$ plates using Cooper CRT-RC2S standard laboratory roller compactor with steel roller. Plates were sawed after one day to a designed beam size of $50 \times 50 \times 300 \mathrm{~mm}$. Before the test beams were conditioned in cooling chamber in test temperature for at least 4 hours, but no longer than 24 hours to avoid the impact of physical hardening on test results.

\section{Testing method}

The three point bending test conducted in Gdansk University of Technology was developed by Judycki [9] and improved by Pszczoła and Judycki [10]. Later it was adapted to run the test in Nottingham Asphalt Tester. $50 \times 50 \times 300 \mathrm{~mm}$ beams were subjected to constant static load for a time of $2400 \mathrm{sec}$ or $3600 \mathrm{sec}$. The applied load depended on the temperature in which the test was conducted and its value was from $30 \%$ to $40 \%$ of the flexural strength. Some of the specimen were subjected to higher value of static load, which exceeded $50 \%$ of the flexural strength. Typical test temperatures were $-20{ }^{\circ} \mathrm{C},-10{ }^{\circ} \mathrm{C}$ and $0{ }^{\circ} \mathrm{C}$. In an extended version of testing, the test was also conducted at temperature of $+10^{\circ} \mathrm{C}$. The strain at the bottom of the specimen was measured with a LVDT sensor. The view of the specimen during the creep bending test and the scheme of the tested beam are presented on Figure 2.

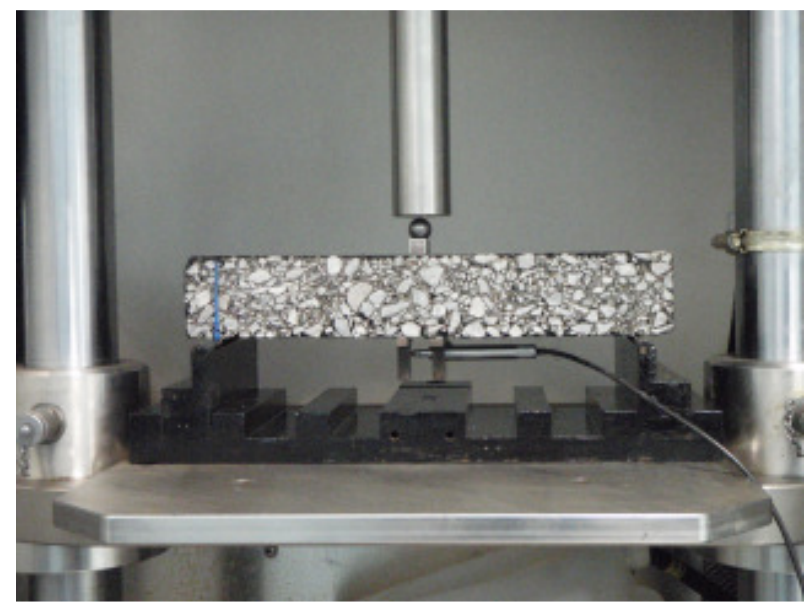

(a)

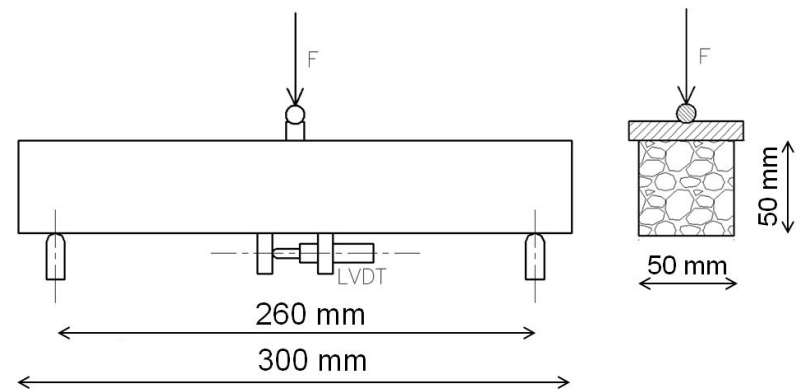

(b)

Fig. 2. Bending creep test of asphalt concrete (a) the specimen inside the Nottingham Asphalt Tester and (b) scheme of the specimen 


\section{Test results and analysis}

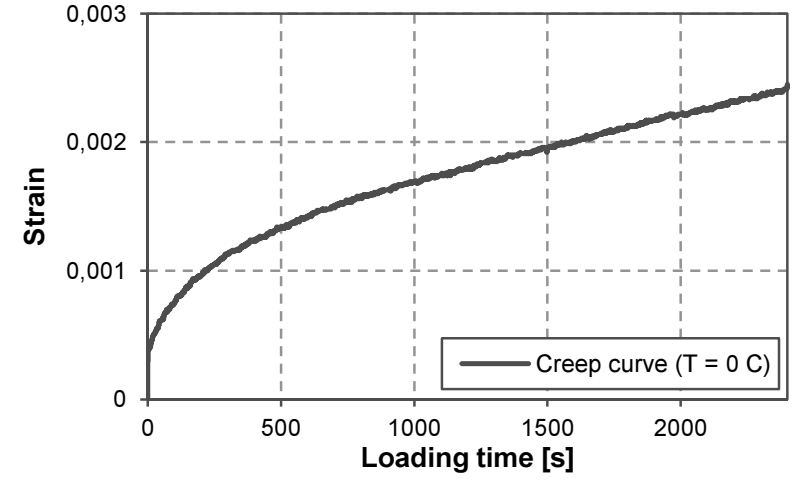

(a)

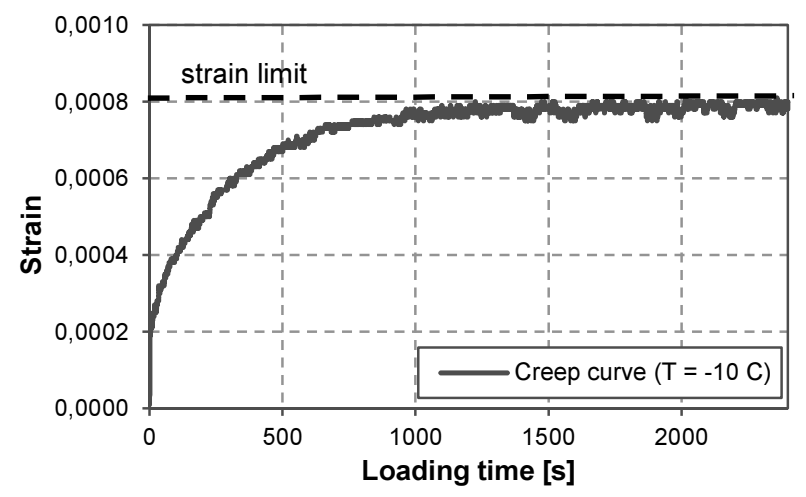

(b)

Fig. 3. Examples of test results: (a) creep curve with viscous flow; (b) creep curve without viscous flow

Figures $3 \mathrm{a}$ and $3 \mathrm{~b}$ present typical results from the three point creep bending test. Figure $3 \mathrm{a}$ presents typical creep curve with viscous flow of asphalt concrete under constant load. At long time of loading strain increases linearly with time and the slope of strain depends on tested material and level of static load applied to the tested beam. Results obtained at temperature of $0^{\circ} \mathrm{C}$ and $+10^{\circ} \mathrm{C}$ in most cases presents this type of behavior. Figure $3 \mathrm{~b}$ presents creep curve where viscous flow is not visible. The strain approaches a specific limit and does not increase with the time of loading. The limit of strain is reached usually after time of loading equal to from 600 to 1200 seconds. Results obtained at temperatures of $-10{ }^{\circ} \mathrm{C}$ and $-20{ }^{\circ} \mathrm{C}$ in most cases presented this type of behavior.

Each asphalt concrete was tasted under the same levels of static load. In some of tested mixtures there were the following deviations from two typical behaviors presented above:

- AC WMS 16 high modulus asphalt concrete with 20/30 multigrade bitumen showed viscous flow up to test temperature of $-10{ }^{\circ} \mathrm{C}$, and deviations from time-temperature superposition principle started at $-20^{\circ} \mathrm{C}$.

- AC WMS 16 high modulus asphalt concrete with 20/30 neat bitumen did not show viscous flow even at test temperature of $0{ }^{\circ} \mathrm{C}$, the deviations started at $0{ }^{\circ} \mathrm{C}$.

- AC WMS 16 high modulus asphalt concrete with SBS modified bitumen at test temperature of $-10^{\circ} \mathrm{C}$ showed some viscous flow, but the rate of viscous flow decreased with time.

As stated before in most cases the value of $30-40 \%$ of the flexural strength was used as applied constant stress. There was possibility that the applied stress was too small to induce viscous flow. Tests with higher static load (up to $50 \%$ of flexural strength) were conducted to examine such possibility. Results of these tests are presented in Figure 4 . Creep curves measured under two static load levels ( $40 \%$ and $50 \%$ of the flexural strength) show different limits of strain at long time of loading. Three specimen were used for each load level. Limit of strain for static load of $50 \%$ of flexural strength is higher than for lower static load $-40 \%$ of the flexural strength, but it also reaches constant value after time of loading of about 600 to 1000 seconds. It can be seen that the time at which strain reaches constant limit increases with higher levels of static load.

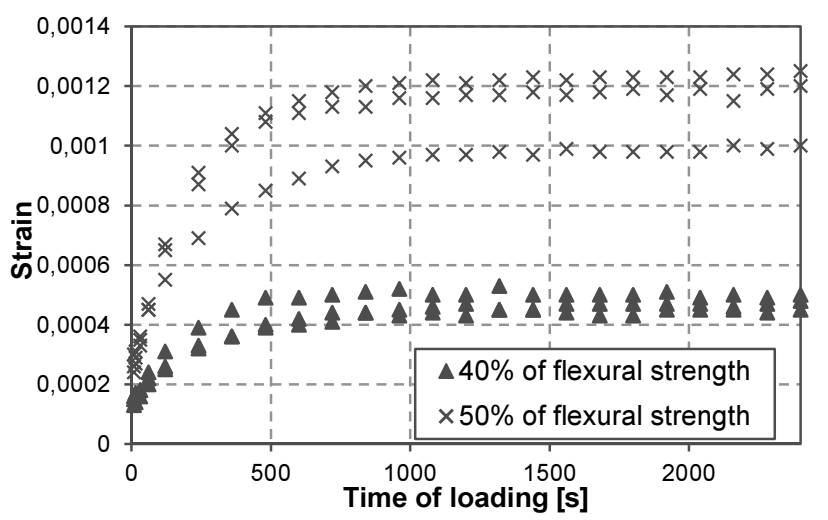

Fig. 4. Impact of different levels of static load on behavior of asphalt mix at creep (creep curves for AC WMS16 high modulus asphalt concrete with $20 / 30$ neat bitumen at temperature of $-20^{\circ} \mathrm{C}$ ) 


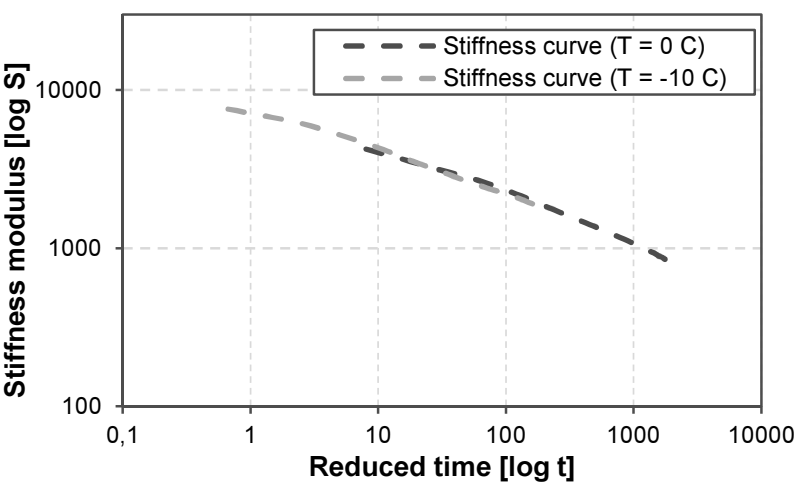

(a)

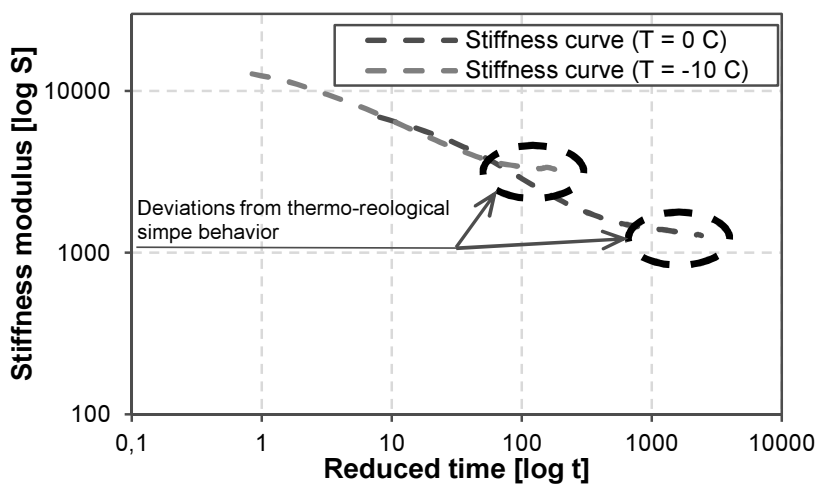

(b)

Fig. 5. Shifting of stiffness curves: (a) AC WMS16 high modulus asphalt concrete with 20/30 multigrade bitumen;

(b) AC WMS16 high modulus asphalt concrete with 20/30 neat bitumen

The described type of behavior has great impact on developing of master curves of stiffness modulus. As presented earlier stiffness curves created from creep curves obtained at different temperatures should coincide with each other after shifting. Figure 5a presents shifting of stiffness curves obtained from bending test of AC WMS16 high modulus asphalt concrete with $20 / 30$ mutligrade bitumen at temperatures of $-10{ }^{\circ} \mathrm{C}$ and $0{ }^{\circ} \mathrm{C}$. The shifted stiffness curve for temperature of $10^{\circ} \mathrm{C}$ covers stiffness curve for temperature of $0{ }^{\circ} \mathrm{C}$ without any deviations. Figure $5 \mathrm{~b}$ presents shifting of stiffness curves obtained from bending test of AC WMS16 high modulus asphalt concrete with 20/30 neat bitumen. The deviations from thermo-reologically simple behavior are visible for shifted stiffness curve at temperature of $-10^{\circ} \mathrm{C}$. Part of the stiffness curve for times of loading lower than around 600 to 1000 seconds covers stiffness curve at temperature of $0{ }^{\circ} \mathrm{C}$. Second part of stiffness curve for times of loading higher than around 600 to 1000 seconds does not cover the stiffness curve at $0{ }^{\circ} \mathrm{C}$. This second part of the curve at $-10^{\circ} \mathrm{C}$ diverges from linear behavior and reaches nearly constant value of stiffness modulus, giving a characteristic "tail" which can be seen in Figure 5 b.

The master curves of stiffness modulus which were developed using stiffness curves obtained from tests at temperatures of $+10,0,-10$ and $-20{ }^{\circ} \mathrm{C}$ were described using the five parameter general sigmoidal Eqn. (4) presented in [11]:

$$
\log S=\delta+\frac{\alpha-\delta}{\left[1+\lambda e^{(\beta+\gamma(\log 1 / t))}\right]^{1 / \lambda}}
$$

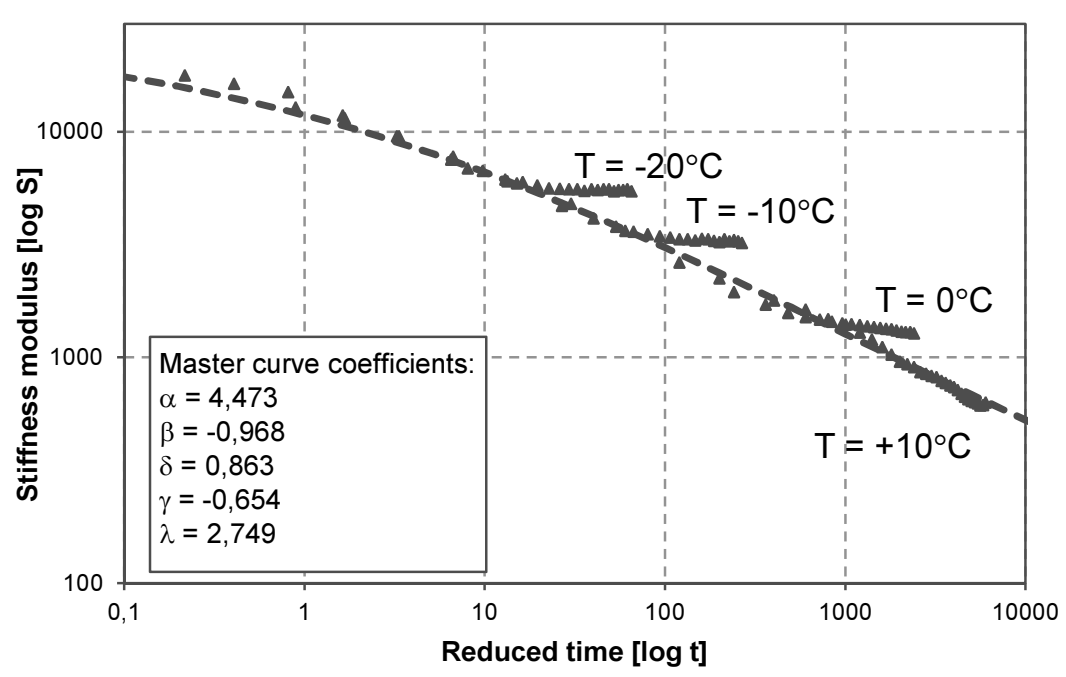

Fig. 6. Master curve developed for AC WMS16 high modulus asphalt concrete with 20/30 neat bitumen using Eqn. (4) 


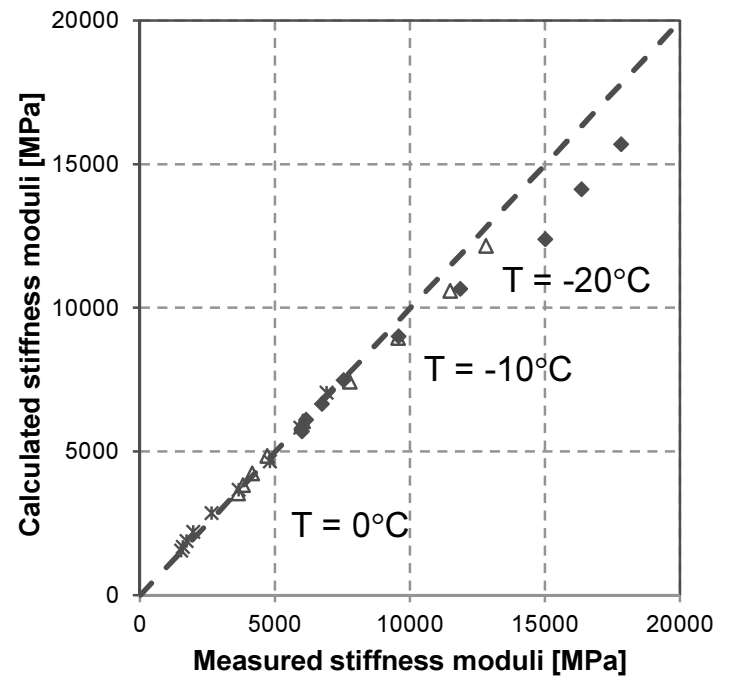

(a)

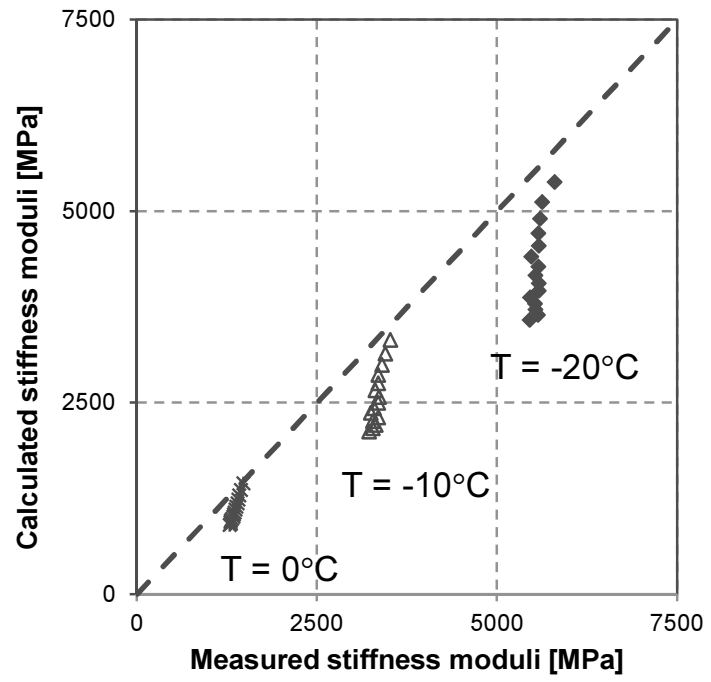

(b)

Fig. 7. Comparison between measured and calculated stiffness moduli of AC WMS16 high modulus asphalt concrete with 20/30 neat bitumen for: (a) loading time shorter than 600 seconds (b) loading time longer than 600 seconds

In Eqn. (4) the coefficient $\alpha$ describes upper asymptote and was determined from indirect tensile stiffness modulus test at temperature of $-30{ }^{\circ} \mathrm{C}$. To determine the $\beta, \delta, \gamma$ and $\lambda$ coefficients the EXCEL SOLVER software was used. The function which was used to determine the equation coefficients in the EXCEL SOLVER software was the least square function of measured and calculated stiffness modulus. As an example a master curve developed for AC WMS16 high modulus asphalt concrete with 20/30 neat bitumen is presented in Figure 6. The master curve in Figure 6 has three characteristic "tails" which result from the deviation from the thermo-rheological simplicity.

Figure 7 presents comparison between stiffness modulus measured in the creep bending test and calculated form the master curve equation for the AC WMS16 high modulus asphalt concrete with 20/30 neat bitumen. It can be seen that for the time of loading shorter than 600 seconds the measured and calculated moduli are equal or similar. For the loading time longer than 600 seconds the measured and calculated values of moduli differ due to the deviations from the thermorheological simplicity. The measured values of moduli at time of loading longer than 600 seconds are nearly constant for each of tested temperatures and are much higher than the moduli calculated from the master curve equation.

\section{Conclusions}

1. Different types of asphalt mixtures were tested in creep bending test to determine stiffness curves for master curve development. In many cases the deviations from the thermo-rheological simplicity were observed.

2. The deviations were observed in almost all of specimens tested at temperatures lower than or equal to $-10{ }^{\circ} \mathrm{C}$. In only one case (AC WMS16 high modulus asphalt concrete with 20/30 multigrade bitumen) deviation at temperature of $-10{ }^{\circ} \mathrm{C}$ was not observed but was evident for this mix at $-20^{\circ} \mathrm{C}$. In some cases (e.g. AC WMS16 high modulus asphalt concrete with $20 / 30$ neat bitumen) the deviation was observed even at temperature of $0{ }^{\circ} \mathrm{C}$. The specimens tested at temperature of $+10^{\circ} \mathrm{C}$ did not show any deviations from the thermo-rheological simplicity.

3. The deviations from the thermo-rheological simplicity were observed for the longer loading times. The deviations started at times of loading around 600 to 1200 seconds. The start of deviations depended on the type of asphalt mixture and used bitumen, test temperature and the value of load applied to the test specimen.

4. The deviations were observed for different levels of static load. For higher levels of static loads deviation started later.

5. The deviations from the thermo-rheological simplicity have high impact on developing the master curve of stiffness modulus. Shifted stiffness curves obtained at different temperatures do not coincide with each other in all range of time. The developed master curves have the visible "tails".

6. The measured and calculated stiffness moduli are similar for the short times of loading, below 600 or 1000 seconds. For the longer times of loading the measured stiffness moduli were higher than calculated from the master curve equation.

7. The observed deviations may have strong impact on low-temperature properties, e.g. stress relaxation or thermal stresses and need further investigation.

\section{References}


[2] Monismith, C. L.; Alexander, R. L.; Secor, K. E. 1966. Rheological Behavior of Asphalt Concrete, in Proc. of Association of Asphalt Paving Technologies 35: 400-450.

[3] Schwartz, C. W.; Gibson, N.; Schapery, R. A. 2002. Time-Temperature Superposition of Asphalt Concrete at Large Compressive Strains, Transportation Research Record, Journal of the Transportation Research Board 1789(1): 101-112.

[4] Schwartz, C. W.; Gibson, N.; Schapery, R. A.; Witczak, M. 2004. Viscoplasticity Modeling of Asphalt Concrete Behavior, in Recent Advances in Material Characterization and Modeling of Pavement Systems, GSP 123, Columbia University, New York, $2004,144-159$.

[5] Zhao, Y.; Kim, Y. R. 2003. The Time-Temperature Superposition for Asphalt Mixtures with Growing Damage and Permanent Deformation in Compresion, Transportation Research Board 2003 Annual Meeting CD-ROM [online]. [cited 23 January 2014]. Available from Internet: http://www.Itrc.lsu.edu/TRB_82/TRB2003-001902.pdf.

[6] Yusoff, N I. M.; Chailleux, E.; Airey, G. D. 1997. A Comparative Study of the Influence of Shift Factor Equations on Master Curve Construction, International Journal of Pavement Research and Technology 4(6): 324-336.

[7] Palade, L. I.; Attane, P.; Camaro, S. 2000. Linear Viscoelastic Behavior of Asphalt and Asphalt Based Mastic, Rheologica Acta 39(2): 180-190. http://dx.doi.org/10.1007/s003970050018

[8] Marasteanu, M. O.; Basu, A.; Hesp, S. A. M.; Voller, V. 2001. Time-Temperature Superposition and AASHTO MP1a Critical Temperature for Lowtemperature Cracking, International Journal of Pavement Engineering 5(1): 31-38. http://dx.doi.org/10.1080/10298430410001720792

[9] Judycki, J. 1990. Bending Test of Asphaltic Concrete Mixtures Under Statical Loading, in Proc. of IV International RILEM Symposium "Mechanical Tests for Bituminous Mixes - Characterization, Design and Quality Control", Budapest, 1990. Chapman and Hall, $207-233$.

[10] Pszczoła, M.; Judycki, J. 2009. Testing of Low Temperature Behaviour of Asphalt Mixtures in Bending Creep Test, in Proc. of the 7th International Rilem Symposium ATCBM09 on Advanced Testing and Characterization of Bitumnious Materials, Rhodes, Greece, 27-29 May 2009r.

[11] Rowe, G. M.; Sharrock, M. J. 2011. Alternate Shift Factor Relationship fo Describing the Temperature Dependency of the Visco-Elastic Behaviour of Asphalt Materials, Transportation Research Record, Journal of the Transportation Research Board 2207(1): 125-135.

http://dx.doi.org/10.3141/2207-16 